\title{
Game theory application in marketing of innovation activity at industrial enterprises
}

\author{
Alexander Samoldin \\ Associate professor of department «Entrepreneurship and foreign economic activity», Cand. Sc. \\ (Eng.), Bauman University, Moscow
}

\begin{abstract}
The theoretical game approach to analyzing marketing objectives in innovation activity is a reasonable supplement to the traditional methods and models of managing enterprises' marketing. The optimal choice of innovative products is significantly more important for industrial enterprises as unlike the commerce and service sector there are more expenses on the development and production of innovative products. Relatively simple game models allow checking the choice of a marketing strategy for various external conditions.
\end{abstract}

Keywords: manufacturing process management, enterprise, production, marketing, innovation activity.

\section{Introduction}

A production organization is most often understood as a combination of resources (people, mechanisms, materials, finances, and others) integrated into a single system that aims at the production and sale of material goods [1]. Typically, the following functional subsystems of a production organization are distinguished: subsystems that directly provide production processes, including preparatory stages (internal subsystems), and subsystems that ensure the functioning of a production organization in an external environment (external subsystems) [2].

At the same time, significant integration of production and marketing systems from the perspective of a customer-oriented approach is noted [3]. Also, in the new conditions, the functions of controlling in a manufacturing organization are changing $[4,5]$. The modern operating conditions of the production organization are characterized by rapid changes in many parameters and environmental factors. In these conditions, marketing begins to play a key role in the development and functioning of the production organization.

The role of marketing in modern business, in the management of business changes, including innovative changes, has been noted by many world-famous authors: I. Adizes [6], F. Kotler [7], J. Saunders [8] and other researchers. Moreover, almost all authors emphasize the inextricable link between marketing and management within the enterprise (company, association, corporation), which is quite true for a production organization.

Recently, they began to single out the so-called industrial marketing, which is aimed not only at optimizing production and meeting the organization's needs for materials, raw materials, components, finances and other resources, but also at increasing the sales efficiency of industrial goods by researching supply and demand in specialized markets [9]. 


\section{Methods and materials}

The subject of industrial marketing is the relationship between market players that arise as a result of their business activity (technical and economic cooperation, purchase and sale relations, financial relations, business negotiations, competitive relations, technological relations, etc.).

The innovative development of a manufacturing organization is inextricably linked to such important factors as uncertainty and risk. At the same time, when making managerial decisions related to innovative activity, the role of marketing research significantly increases, the results of which can reduce uncertainty and reduce risks.

The terms "innovation", "innovative activity", "innovative marketing" and "marketing of innovations" have no unambiguous definitions and interpretations in the modern scientific literature. Nevertheless, in general, innovation can be understood as an novelty developed and brought to the stage of implementation on the market (usually it is a product or service, although there may be a technology), innovative activity is the process or processes of creating and implementing innovation, and marketing of innovations is marketing support of innovative activities.

Today, in the context of the globalization of the economy, the connection between marketing of a manufacturing organization and innovative activity is particularly clearly traced. One can quite definitely say that the marketing of a production organization is a subsystem of the entire system of innovative activity, so a system approach is applicable to it [10]. At the same time, the marketing activities of a manufacturing organization are carried out in real time, subject to changes depending on external and internal conditions, therefore marketing can also be considered as a process.

Both approaches to marketing - systemic and process, to a certain extent can be combined into a single game theoretic approach. Indeed, a mathematical game is usually determined by the composition of the game participants (players), game rules, which can be understood as the methods and sequence of decision-making by each player, the winnings (losses) of the players, and the order of calculations [11]. Thus, the game is both a system that unites players, and a process in which these players take an active or passive part. Note that the classical methods of game theory have long been used in some marketing problems [12].

Let us now dwell on the features of marketing the innovation activity of a manufacturing organization. First, we divide the marketing of goods (products of a manufacturing organization) and marketing of services. Obviously, there are significant differences.

A product is a thing that possesses the properties of materiality, measurability and admissibility of objective evaluation. This means that any consumer can, if desired, determine the quantity and quality of the goods offered to him. In addition, the product in most cases is returnable.

A service is intangible, not always measurable (for example, time can be used as a unit of measure, but different services can be provided during the same time interval), it is quite difficult to establish the quality of the service, and it is usually irrevocable.

A manufacturing organization can provide its customers with services (transportation, commissioning, repair, etc.), but this is an auxiliary activity of an industrial enterprise. Its main activity is always production of goods, therefore the main structure in the production organization is product marketing.

Now we divide the marketing of production and trade. Trade does not bear the cost of manufacturing goods. There are no such elements in trade as raw materials, materials, fuel, machine tools, equipment, machinery, mechanisms and other elements of production activity. Trade deals with finished products or with semi-finished products intended for sale through a distribution network. Therefore, trade marketing is, first of all, analysis of the consumer market, pricing and organization of the sales network. 
If we consider the marketing of a manufacturing organization (especially the production of new or innovative products), then the main marketing strategy will most likely be a positioning strategy. If we consider the positioning of a product as a process of determining its place among existing goods [13], analyzing the possibility of replacing old goods with it, and so on, then we can determine four main areas of the marketing strategy of an industrial enterprise - a product strategy, a communication strategy, a distribution strategy, and a pricing strategy [14]. At the same time, the main marketing strategic direction for innovative activity will be precisely the product strategy, within which decisions are made on the creation of an innovative product and the development of the product range in breadth and depth. The other three strategic directions remain important as marketing support for innovative activities of the enterprise [15].

The tasks of choosing the optimal product range for the traditional production of a manufacturing organization are well known at the theoretical level and are successfully solved practically (in particular, using methods for solving linear programming problems). The computational process for such tasks is preceded by the development of an appropriate economic and mathematical model and filling it with the necessary information. Unknown for tasks of this kind are usually the volumes of output for individual items of the assortment, and the restrictions are conditions that do not allow to produce more (resource, technological, market capacity, etc.) or less than a certain volume of each type of product.

In the case of innovative products, the situation is much more complicated. Firstly, innovative activity (if we are talking about a really new product, and not about a slight improvement in the old product). This implies significant costs, including: marketing research at the stages of searching and testing innovative ideas, changing the technology of production of goods and/or replacing equipment, licensing and other legal activities, field trials of new goods and others. Secondly, the new product is unknown to the market, therefore, significant marketing efforts are required to commercialize innovative products.

Thirdly, the reaction of the market to an innovative product is not known in advance. Two options are possible here. The first case is that the market reaction is completely unpredictable. This situation arises when a completely new product appears that really has no analogues. In this case, the marketing task of choosing the best innovative product and the corresponding assortment for an existing industrial enterprise can be represented as a mathematical game with nature.

Let us present this problem in the form of a two-person game in which the first player is the marketing of an industrial enterprise, and the second player is the combined consumer market of innovative enterprise goods. Marketing (player 1) makes the move first, choosing one of the alternative innovative products. For each of the alternative innovative products, the costs of its development and launch to the market are known. The market (player 2) reacts to this product. Possible market reactions (in the form of total income from the sale of a new product on the market) and their probabilities are given. Then the gain of the industrial enterprise for each of the alternative innovative products and for each market reaction to this product can be calculated.

Next, alternative innovative product is chosen in accordance with one of the well-known criteria adopted for games with nature:

- Wald criterion or extreme pessimism, when the decision is chosen based on the worst external conditions;

- Hurwitz criterion, when both favorable and unfavorable external conditions are possible;

- Savage criterion when the maximum loss in winnings is minimized;

- Laplace criterion, assuming that all market reaction options are equally likely,

- criterion of maximum gain or extreme optimism and other known criteria. 
A game interpretation of the problem of choosing the optimal product (or assortment of products) from alternative innovative products allows marketers to calculate various results in the future with fairly simple and well-known game-theoretic methods.

In the second case, the market is familiar with analogues and/or substitutes for future innovative products of an industrial enterprise; therefore, its combined meaningful reaction can be expected. By setting market strategies in a non-anthogonistic two-person game (bimatrix game), you can get a pay table for various pure and mixed industrial enterprise strategies for different innovative products. At the same time, one can change the conditions of the game both in terms of market strategies and in terms of the size of winnings of an industrial enterprise, while analyzing the sensitivity of the game to changes in initial conditions.

It seems that game-theoretic methods and models can serve as a good complement for analysis before choosing managerial decisions on the innovative activity of an industrial enterprise at the stage of determining the range of innovative products.

In other areas of innovative activity of a manufacturing organization, it is also possible to use game-theoretic methods and models. In particular, on such models it is possible to play various versions of advertising campaigns and other actions related to the promotion of innovative products on the market, and pricing models for innovative products can be supplemented with "games" with prices.

\section{Results}

Let us consider a few specific gaming applications for marketing the innovation activities of a manufacturing organization.

The staffing of innovative activity is one of the most important and necessary tasks to create a favorable innovation environment. According to A.K. Rassadina, under the growing role of scientific and technological personnel in ensuring the innovative development of production, their shortage is a very acute problem [16].

The task of selecting and training personnel for innovative projects can be formally posed as follows.

There are $N$ alternatives to staffing an innovation project. It is required to find the best option of staffing by the criterion of price-quality. From a marketing standpoint, this means a different cost of marketing efforts for different staffing options for an innovative project. At the same time, the quality of selected or trained personnel can be assessed in cost form for comparison with costs. This problem is quite successfully solved by game methods. But in such a game, it is important to correctly set the conditions of the game and to take into account the social aspects that affect the behavior of players [17].

Pricing is the most important component of the marketing activities of a manufacturing organization in the market [18]. It should be understood that the price of an innovative product of a manufacturing organization should be determined primarily on the basis of an analysis of the needs and opportunities (purchasing power, capacity, etc.) of the market [19].

A game interpretation of the above statement of the pricing problem, taking into account the certainty of the marginal prices of potential buyers, can be represented as follows. There are $M$ potential buyers of an innovative product (players) who have marginal purchase prices known to marketers. Each of the players is ready to make only a single bet (buy a unit of an innovative product). The gain for each unit sale at each set price $C_{i}$ is the difference between it and the unit cost of the innovative product $S$. The total gain is the sum of the individual wins, which is maximized.

Marketing as the first player makes a move by setting the price $C_{i}$ per unit of the innovative product, which is considered optimal at the moment. All buyers (players) react to this price by buying or not buying an innovative product unit. The reaction of customers 
to the pricing of the innovation structure can be defined by a binary matrix. Then the best move (price) for marketing is found.

The simplest game above has several development options. The first option is the transition from single buyers to segments with similar market behavior (aggregation). A further complication of the game can be considered accounting for uncertainty and risk when setting prices for an innovative product.

\section{Conclusions}

In conclusion, we present several arguments in favor of game theory versus probability theory and statistical methods.

Firstly, probability theory takes randomness into account as a kind of chaotic state, and game theory assumes the conflict and rationality of players, which distinguishes it favorably in economic applications [20].

Secondly, often in the economy there are situations in which two or more parties are involved, pursuing different goals. Such situations are usually called conflict [21]. In the interaction, each side seeks to obtain the greatest gain for themselves when resolving a conflict situation. Accounting for such situations is easier to formalize in a mathematical game.

Thirdly, the target functions and limitations of the marketing management system of innovative activity cannot be called uniquely defined for any conditions. Criteria and restrictions may change significantly in the process of implementing innovative activities due to changes in foreign policy conditions, domestic policy of the state, market conditions or for other reasons. Game applications allow one to change the conditions of the game, the composition of players, etc., which makes game models more appropriate to the real situation.

Fourthly, marketing of innovations affects not only the internal divisions of the innovation structure, but also a significant number of external partners (contractors, intermediaries, sellers, etc.) who have their own interests and are not formally subordinate to the leadership of the innovation structure or innovation project.

Finally, many game models can be relatively easily formalized and implemented at the software level. At the same time, it remains possible to search for optimal solutions for games in the interpretative mode. Thus, the game-theoretic approach to marketing the innovation activity of an industrial enterprise can be considered justified.

\section{References}

1. Golub N.N. Features of the production of complex high-tech products // Bulletin of the Voronezh State Technical University. 2012. No. 1. p. 65-69.

2. Razdorozhniy A.A. Organization of production and enterprise management. Moscow, Ekzamen. 2009. 877 p.

3. Petrov V.Yu., Petrova P.I. Integration of production and marketing systems from the perspective of a customer-oriented approach // Fundamental Research. 2015. No. 3. P. 202-206.

4. Falco S.G. Controlling for managers and professionals. Moscow, Finance and statistics. 2008. 256 p.

5. Falco S.G. Transformation of controlling tools in modern conditions // Controlling. 2014. No. 51. p. 3-7.

6. Adizes I.K. Managing change. Saint-Petersburg, Piter. 2008.222 p.

7. Kotler F. Marketing management. Saint-Petersburg, Piter. 2000.472 p. 
8. Kotler F., Armstrong G., Saunders J., Wong V. Fundamentals of marketing / 2nd Europe. ed. Moscow; Saint-Petersburg; K.: Williams Ed. House. 2007.944 p.

9. Iskoskov M.O., Kargina E.V. The marketing system management model at the enterprises of the industrial sector // Bulletin of the Volga University. 2019. No. 3.T. 2. p. 92-98.

10. Goncharova A.V., Kurcheeva V.I. System and process approaches to innovation marketing management // Economic analysis: theory and practice. 2013. No. 39. p. 2634.

11. Pisaruk N.N. Introduction to game theory. Minsk: BSU. $2015.245 \mathrm{c}$.

12. Krasnov V.K., Pichuzhkin A.B., Smirnova T.N. The use of classical methods of game theory in marketing problems // Bulletin of the Russian University of Cooperation. 2014. No3 (17). p. 145-148.

13. Gofman A.E. Marketing as a guide for the innovative development of industrial enterprises // Bulletin of the Omsk University. 2012. No. 3. P. 337-341.

14. Volovikov B.P. Approaches to the formation of the concept of innovative marketing of industrial enterprises // Siberian Trade and Economic Journal. No. 1 (17). 2013.S. 56-64.

15. Krasnov A.I. Features of managing innovative processes of an industrial enterprise on the basis of their marketing support // Actual problems of economic sciences. 2008. No. 1. p. 92-96.

16. Rassadina A.K. Personnel support of innovative economy. Experience of economically developed countries // Vestnik MSU. Series 6. Economics. 2011. No 1. p. 109-120.

17. Samoldin A.N., Aglitskiy I.S. Conducting marketing research in the field of innovation with regard to socio-economic aspects // Labor and social relations. 2014. No. 7. p. 5459 .

18. Kovalev V.V. Introduction to financial management. Moscow, Finance and statistics. $2001.768 \mathrm{p}$.

19. Popovich L.G., Drogovoz P.A., Kalachanov V.G. Management of innovation and investment activities of the enterprise of the military-industrial complex in the conditions of diversification: Monograph. Moscow, Vash format, 2018. $228 \mathrm{p}$.

20. Trukhaev R.I. Models of decision making in conditions of uncertainty. Moscow, Science. $1981.258 \mathrm{p}$.

21. Soloviev V.I. Methods of optimal solutions: a training manual. Moscow, Financial University. 2012. p. 113. 